\title{
When is an Offset Not an Offset? A Framework of Necessary Conditions for Biodiversity Offsets
}

\author{
Jenny Pope $\mathbb{1}^{1,2} \cdot$ Angus Morrison-Saunders ${ }^{2,3} \cdot$ Alan $^{\text {Bond }}{ }^{2,4} \cdot$ Francois Retief $^{2}$ \\ Received: 12 July 2020 / Accepted: 17 December 2020 / Published online: 22 January 2021 \\ (c) The Author(s), under exclusive licence to Springer Science+Business Media, LLC part of Springer Nature 2021
}

\begin{abstract}
Biodiversity offsets have become a widely accepted means of attempting to compensate for biodiversity loss from development, and are applied in planning and decision-making processes at many levels. Yet their use is contentious, and numerous problems with both the concept and the practice have been identified in the literature. Our starting point is the understanding that offsets are a kind of biodiversity compensation measure through which the goal of no net loss (or net gain) of biodiversity can be at least theoretically achieved. Based on a typology of compensation measures distinguishing between habitat protection, improvement (including restoration, habitat creation and improved management practices) and other compensation, we review the literature to develop a framework of conditions that must be met if habitat protection and improvement initiatives can be truly considered offsets and not merely a lesser form of compensation. It is important that such conceptual clarity is reflected in offset policy and guidance, if offsets are to be appropriately applied and to have any chance of fully compensating for biodiversity loss. Our framework can be used to support the review and ongoing development of biodiversity offset policy and guidance, with the aim of improving clarity, rigour and therefore the chances that good biodiversity outcomes can be achieved.
\end{abstract}

Keywords Biodiversity offsets $\cdot$ Biodiversity compensation $\cdot$ Mitigation hierarchy $\cdot$ No net loss $\cdot$ Net gain $\cdot$ Offset policy

\section{Introduction}

Biodiversity offsets have been defined by the Business and Biodiversity Offsets Programme ${ }^{1}$ as 'measures taken to compensate for any residual significant, adverse impacts that cannot be avoided, minimised and/or rehabilitated or restored, in order to achieve no net loss or a net gain of

Jenny Pope

jenny@integral-sustainability.net

1 Integral Sustainability, South Fremantle, WA, Australia

2 Research Unit for Environmental Sciences and Management, North-West University, Potchefstroom, South Africa

3 School of Science, Edith Cowan University, Joondalup, WA, Australia

4 School of Environmental Sciences, University of East Anglia, Norwich, UK

\footnotetext{
${ }^{1}$ BBOP describes itself as 'an international collaboration between companies, financial institutions, governments and civil society organisations working towards a net gain of biodiversity' (www.foresttrends.org/bbop/).
}

biodiversity' (BBOP 2012, p 1). They are increasingly being applied as part of numerous different planning and decision-making mechanisms operating at different levels; for example, Maron et al. (2018) distinguish between biodiversity offsets applied in overarching policies, and those applied in relation to a specific impact from a specific development. One important mechanism through which the second type of offsets may be applied is environmental impact assessment (EIA) (BBOP 2009a), arguably the preeminent and most widely used environmental management mechanism globally (Morgan 2012; UNEP 2018). In EIA, biodiversity offsets are typically positioned as the 'last resort' option in the mitigation hierarchy, to be applied when options for on-site biodiversity impacting avoidance, minimisation and restoration have been exhausted (BBOP 2012).

Biodiversity offsets are appealing to developers and often also to regulators, since they appear to offer a 'best of all worlds' solution to the trade-offs inherent in the vast majority of development approvals in which some level of adverse environmental impact is unavoidable. There are numerous increasingly insistent voices, however, arguing that there are fundamental issues with both the concept and 
the practice of biodiversity offsets, with grounds for challenge ranging from the ecological, to the practical, to the economic, to the moral and philosophical, all of which are connected to some extent (Spash 2015; Maron et al. 2016a, b; Apostolopoulou and Adams 2017; Levrel et al. 2017; Primmer et al. 2019).

There is also an argument that the theory and practice of biodiversity offsets is conceptually murky, and this is the area in which this paper contributes. At the most basic level, several researchers have reported confusion between offsets and other mitigation measures, finding that actions may be incorrectly denoted as offsets when in fact they are examples of avoidance, minimisation or restoration of impacts (i.e., earlier steps in the mitigation hierarchy) on a development site (Bidaud et al. 2017; Bigard et al. 2017). However, for the purposes of this paper, we adopt the view that by definition, offsets seek to compensate for impacts on the development site in another place that is outside the development envelope and therefore there can be no real confusion between offsets and the other steps in the mitigation hierarchy.

A more significant conceptual challenge lies in the question of whether all biodiversity compensation measures can be considered offsets. Although the terms 'compensation' and 'offset' are often used in conjunction, as in the BBOP definition cited earlier (BBOP 2012) or even interchangeably (de Witt et al. 2019), for the purposes of this paper, we take the view that offsets are in fact a subset of compensations, such that all offsets are compensations but not all compensations are offsets. This is in line with literature that highlights that there are certain principles that offsets should reflect, a key one of which is the principle of no net loss, or even net gain of biodiversity (BBOP 2012; Brownlie et al. 2013). While this is a useful starting point in distinguishing between offsets and other compensations, it begs the question of under what conditions no net loss (or net gain) might actually be achieved. There have also been many contributions that have provided partial answers to this question; what has been lacking, however, is a consolidation of this work into a clear framework specifying the conditions with which biodiversity offsets should comply. The development of such a framework is the purpose of this paper. Therefore our research question is:

What are the necessary conditions for biodiversity compensation measures to be considered offsets?

The framework of necessary conditions for biodiversity offsets developed in this paper is intended to inform both the development and review of policy and guidance related to biodiversity offsets, with the ultimate goal of ensuring that biodiversity offsets are designed to achieve at least no net loss of biodiversity. We do not take the next step of evaluating from a conservation perspective the success or otherwise of on-the-ground offset initiatives. We recognise there is much work on this topic in the realm of conservation biology, but our focus here is on the design of biodiversity offsets from a policy perspective. We hope that our framework will prove useful as a basis for comprehensive reviews of policy and guidance frameworks in the future.

\section{Methodology}

The methodology for developing our framework of necessary conditions for biodiversity offsets was based primarily on literature review, broadly following Jabareen's (2009) stepwise approach to constructing a conceptual framework.

Step 1 was the conduct of a literature review on biodiversity offsets. This involved database searches using Google Scholar and Scopus for academic literature focussing on biodiversity offsets, biodiversity compensation, no net loss and net gain. This was supplemented by following citations and use of citation indexes to follow lines of debate. Literature on biodiversity offsets and compensations spans very diverse academic subjects, so we found limited value in focussing on particular journals or even subject areas, but rather used the database search functions to ensure a broad search.

Step 2 was analysis of the literature to identify a 'skeleton framework', defined as comprising 'characteristics derived from previous enquiry that provide an internal structure that provides a starting point for observations... and for analysis' (Jabareen 2009, p 50). In this case, the process followed was to first review literature on 'offsets' and 'compensations' in order to distinguish between the two at a high level ('Offsets versus compensation'). We then identified a suitable typology of biodiversity compensation measures (see 'Types of biodiversity compensation measure' below) that provides the structure for our own, more detailed framework.

Our main contribution comes in Step 3, in which we undertook further analysis of literature to 'pad out' and 'give flesh to' (Jabareen 2009, p 50) this typology. This iterative process resulted in our framework of conditions under which biodiversity compensation measures can be considered offsets (see 'Habitat protection' and 'Improvement' below). It is important to note that our framework represents the current state of agreement in the offset literature; it is expected that as research and practical experience in this area develop further that more detail and nuance can potentially be added in the future.

As part of the process of developing our framework, in Step 4, we applied components of our framework to offset policies and guidelines in jurisdictions with which we are familiar (Australia, South Africa and the European Union) 
to illustrate key points, validate the framework and demonstrate its utility as an analytical tool.

\section{Identifying Necessary Conditions for Biodiversity Offsets}

\section{Offsets Versus Compensation}

As highlighted in 'Introduction', the terms 'offsets' and 'compensation' have been used in conjunction, or interchangeably in the literature. For example, each term may appear as the final step in the mitigation hierarchy, to be applied when all other means of avoiding, minimising and restoring biodiversity impacts have been exhausted. Many different forms of the mitigation hierarchy exist in different jurisdictions today (Ten Kate et al. 2004). Perhaps, the oldest version is provided in the United States Council on Environmental Quality guidelines as follows (CEQ 1978, s. 1508.200):

'Mitigation includes:

(1) Avoiding the impact altogether by not taking a certain action or parts of an action;

(2) Minimising impacts by limiting the degree or magnitude of the action and its implementation;

(3) Rectifying the impact by repairing, rehabilitating, or restoring the affected environment;

(4) Reducing or eliminating the impact over time by preservation and maintenance operations during the life of the action; and

(5) Compensating for the impact by replacing or providing substitute resources or environments [emphasis added]'.

This is very similar to the BBOP (2012) version mentioned in 'Introduction' (impact avoidance, minimisation, restoration and offset), except that the term 'offset' appears as the final stage instead of 'compensation'. It does appear that the term 'offsets' is relatively new, a phenomenon of the 21 st century, with initial draft policy and discussion papers for different jurisdiction emerging after 2000, for example in Australia (NSW DLWC 2001; NSW EPA 2002; WA EPA 2006), United Kingdom (HM Government 2011) and South Africa (DEADP 2007; DEA 2017), as well as from the IUCN (Ten Kate et al. 2004). As previously mentioned, however, BBOP and others draw a clear distinction between the two terms, arguing that offsets are a specific type of compensation and that a compensation measure can only be considered an offset if it meets certain principles and associated criteria or conditions (Moilanen et al. 2009; Walker et al. 2009; BBOP 2012). Our starting point is therefore at the level of principles for biodiversity offsets. There are numerous sets of such principles that can be found in almost any piece of guidance on the subject. For the purposes of this paper, we will refer to the principles outlined in BBOP $(2009 \mathrm{~b})$, which are presented in Table 1 below.

Some of these principles require further, more detailed examination. For example, Principle 1 begs the question 'no net loss of what?' Does no net loss refer to species, ecosystem function or ecosystem services, for example (Bull et al. 2013a, b)? Gardner et al. (2013, p 1257) argue that it should mean 'no net reduction in the diversity within and among species and vegetation types; long-term viability of species and vegetation types (i.e., ensuring minimum population sizes and areas of occupation); and functioning of species assemblages and ecosystems (including ecological and evolutionary processes)'.

Inherent within this explanation of no net loss is the notion of equivalence or 'like-for-like'. Some other policy documents (e.g., DEA 2017) include like-for-like as a separate principle, whereas BBOP (2009b) does not. However the BBOP document does emphasise the importance of this concept (p 30):

'Biodiversity offset policies around the world are often based on the principle of 'LIKE-FOR-LIKE or better'. The most desirable outcome is generally to offset the biodiversity components to be impacted by targeting the same biodiversity components elsewhere (an 'in-kind' offset)'.

For clarity, we have elected to include 'the Principle of Like-for-Like' as a separate principle in our analysis

Reference to biodiversity offset principles features in various arguments as to which subset of compensation measures can be considered offsets. In the discussion of the literature that follows, we provide our interpretation of which principles are reflected (in brackets), in accordance with the list above. For Bull et al. 2013a, b, p 371, compensations can only be considered offsets if '(1) they provide additional substitution or replacement for unavoidable negative impacts of human activity on biodiversity, (2) they involve measurable, comparable biodiversity losses and gains, and (3) they demonstrably achieve, as a minimum, no net loss of biodiversity'. These criteria reflect the principles of additional conservation outcomes (Principle 2), the Principle of Like-for-Like, and no net loss (Principle 1). In turn, Gardner and von Hase (2012) emphasise that offsets should be comparable to the impacted environmental value (the Principle of Like-forLike), additional (Principle 2) and lasting (Principle 8). Any other measure would by definition be only a compensation measure and not an offset. BBOP suggests that the most common reasons why a particular compensation 
Table 1 BBOP Biodiversity Offsets Principles (BBOP 2009b, p 16)

BBOP principle Definition

Principle 1 -no net loss

Principle 2-additional conservation outcomes

Principle 3-adherence to the mitigation hierarchy

Principle 4-limits to what can be offset

Principle 5-landscape context

Principle 6-stakeholder participation

Principle 7—equity

Principle 8-long-term outcomes

Principle 9-transparency

Principle 10 — science and traditional knowledge
A biodiversity offset should be designed and implemented to achieve in situ, measurable conservation outcomes that can reasonably be expected to result in no net loss and preferably a net gain of biodiversity.

A biodiversity offset should achieve conservation outcomes above and beyond results that would have occurred if the offset had not taken place. Offset design and implementation should avoid displacing activities harmful to biodiversity to other locations.

A biodiversity offset is a commitment to compensate for significant residual adverse impacts on biodiversity identified after appropriate avoidance, minimisation and on-site rehabilitation measures have been taken according to the mitigation hierarchy.

There are situations where residual impacts cannot be fully compensated for by a biodiversity offset because of the irreplaceability or vulnerability of the biodiversity affected.

A biodiversity offset should be designed and implemented in a landscape context to achieve the expected measurable conservation outcomes taking into account available information on the full range of biological, social and cultural values of biodiversity and supporting an ecosystem approach.

In areas affected by the project and by the biodiversity offset, the effective participation of stakeholders should be ensured in decision-making about biodiversity offsets, including their evaluation, selection, design, implementation and monitoring.

A biodiversity offset should be designed and implemented in an equitable manner, which means the sharing among stakeholders of the rights and responsibilities, risks and rewards associated with a project and offset in a fair and balanced way, respecting legal and customary arrangements. Special consideration should be given to respecting both internationally and nationally recognised rights of indigenous peoples and local communities.

The design and implementation of a biodiversity offset should be based on an adaptive management approach, incorporating monitoring and evaluation, with the objective of securing outcomes that last at least as long as the project's impacts and preferably in perpetuity.

The design and implementation of a biodiversity offset, and communication of its results to the public, should be undertaken in a transparent and timely manner.

The design and implementation of a biodiversity offset should be a documented process informed by sound science, including an appropriate consideration of traditional knowledge. measure might fail to meet the principles and criteria for offsets are (BBOP 2012, p 13):

- 'The conservation actions were not planned to achieve no net loss (Principle 1);

- The residual losses of biodiversity caused by the project and gains achievable by the offset are not quantified (Principles 1 and 8);

- No mechanism for long-term implementation has been established (Principle 8);

- It is impossible to offset the impacts (for instance, because they are too severe or pre-impact data are lacking, so it is impossible to know what was lost as a result of the project) (Principle 4);

- The compensation is through payment for training, capacity building, research or other outcomes that will not result in measurable conservation outcomes on the ground (Principles 1 and the Principle of Like-for-Like)'.

Our review thus far suggests that some principles are related to the definition of an offset and are thus substantive, while others are more procedural or governance-related. The substantive principles are fundamental to distinguishing biodiversity offsets from compensation measures more broadly; these are principles 1, 2, 4, 8 and the Principle of Like-for-Like.

In turn, some of these principles are dependent on others; for example, it is not possible to achieve no net loss (Principle 1) unless long-term outcomes are achieved (Principle 8) and the offsets are like-for-like (the Principle of Like-for-Like). The principle of no net loss (Principle 1) is also closely related to that of additional conservation outcomes (Principle 2) since measures to achieve no net loss with respect to certain biodiversity values should be over and above measures already being taken, and should not detract from them.

Achieving consistency with these principles is therefore no simple matter in practice. In order to explore the conditions under which this might be possible, thus distinguishing between offsets and compensation, it is important to first consider in more detail the types of biodiversity compensation measures that may be applied.

\section{Types of Biodiversity Compensation Measure}

Numerous typologies of biodiversity compensation measures (including offsets), exist in the literature. For example, 
Maron et al. 2012, p 142 distinguish two ways in which offsets can be achieved at an offset site: '(1) via averted loss from ongoing or anticipated impacts (e.g., avoided deforestation or degradation) at a site through the removal of threatening processes and (2) by enhancement of a degraded site through restoration and rehabilitation ('restoration offsets')'. Included in their definition of restoration is the creation of a new habitat, as well as the recreation of habitat 'on a highly degraded site through revegetation' (p 144). Bull and Strange (2018) make a similar distinction, using the terminology of 'avoided loss' and 'ecological restoration'. Both of these forms of compensation can potentially be offsets, depending on how they are applied in practice. Bezombes et al. (2019), in contrast, mention restoration, creation and maintenance of favourable habitat, where maintenance seems to equate to habitat protection.

Other authors include in their typologies measures that do not meet the fundamental principles listed above and which we would therefore argue are compensations, but not offsets. For example, Jacob et al. (2016) identify the following compensation measures: ecological engineering, transplantation, management, knowledge acquisition and awareness raising, where according to the arguments above, the last two are not offsets, whereas if ecological engineering, transplantation and management are equated to improvements as outlined above than they could be.

Compensation can thus be framed in terms of substitution (Brownlie et al. 2013; CEQ 1978), or alternatively as trade-offs (Morrison-Saunders and Pope 2013) or perhaps more cynically as a barter (Walker et al. 2009). Such substitutions, trade-offs or barters may occur in three ways: in time, in place or in kind (Gibson et al. 2005, p 127). All onthe-ground offsets (and compensations) are substitutions in place by definition, whereas the meaning and implications of substitutions in kind and time require further discussion. While Brownlie et al. (2017) argue that any substitutions in kind of biodiversity cannot be considered offsets due to violation of the Principle of Like-for-Like, others (e.g., BBOP 2012 as discussed earlier) leave the door open for the concept of 'like for better'. 'Like for better' implies that substitution in kind of biodiversity might be acceptable under certain conditions, whereas substitutions in kind of capital-for example substituting financial capital for natural capital, a practice that has been viewed as 'buying' an approval (Hayes and Morrison-Saunders 2007)—can be considered a compensation at best but not an offset.

Some offsets embody an inherent time lag, since it takes time for restoration, habitat creation or management efforts to deliver biodiversity outcomes, and thus represent substitutions in both time and place. This raises questions about whether substitution in time is acceptable at all, and if so how the time lag should be taken into consideration in the design of the offsets, as discussed further later in the paper.
In the typology that follows and which structures the remainder of the paper, we have elected to use the terms 'habitat protection' and 'improvement' in relation to biodiversity compensation measures, instead of the more common 'impact avoidance' and 'restoration', to avoid confusion with the steps of the mitigation hierarchy. We also consider improvement to be a more general term than restoration, as it more clearly encompasses the situation in which an entirely new habitat might be created, whereas restoration might be logically interpreted as not including habitat creation. Drawing the threads of the preceding discussion together, we will use the following typology of biodiversity compensation measures as our 'skeleton framework', some of which could be offsets under the right conditions:

- Habitat protection, i.e., protecting biodiversity values by avoiding impacts elsewhere (substitution in place). [It is important to reiterate here that the avoidance step on the mitigation hierarchy of CEQ (1978) is directed to impacts at the actual development site; here the focus is upon avoidance of impact on biodiversity at a remote offset site].

- Improvement, which could include ecological restoration of degraded habitat, the creation of an entirely new habitat or threat management, such as removal of weeds and feral (non-indigenous) animals (substitution in place and time).

- Other compensation, such as research, education and financial compensation (substitution in kind).

Measures within the third category of 'other compensation' as defined above are not offsets because they cannot directly ensure no net loss of biodiversity, whereas habitat protection and improvement measures may or may not be, depending upon how they are applied. Thus, the question becomes, under what conditions can these forms of biodiversity compensation really be considered offsets? We review the literature in relation to this question for each element of our typology in the following sections.

\section{Habitat Protection}

'Habitat protection' essentially means that biodiversity values that are impacted in one location are protected in another location instead, i.e., a substitution in place by definition (Griffiths et al. 2019), but preferably not in time or kind. For example, suitable land may be purchased by the developer and contributed to the conservation estate. There are a number of conditions that must be met, however, for habitat protection measures to be considered offsets.

First and foremost, the biodiversity values in the substituted place should be the same as those in the offset area, 
i.e., the biodiversity values should be like-for-like or better (the Principle of Like-for-Like). Some authors (e.g., McKenney and Kiesecker 2010) consider that to enable like-for-like, offset locations should be physically close to the impacted site, for example, be in the same geographic region and the same watershed (noting, however, that offsets cannot by definition be within the development envelope).

The Principle of Like-for-Like is, however, not uncontroversial. In some cases, 'like-for-like' may be impossible to achieve as there may simply not be suitable land available for purchase by developers (Brown et al. 2014). While it could be argued that this means that impacts become nonoffset-able (Principle 4), there is also an argument that biodiversity conservation objectives can sometimes better be served by allowing substitutions in kind of biodiversity, which is sometimes referred to as 'trading up' (Brown et al. 2014) or 'like for better' (Gardner et al. 2013). BBOP 2009b, p 30 makes this point:

'In certain situations, however, the biodiversity to be impacted by the project may be neither a national nor a local priority, and there may be other areas of biodiversity that are a higher priority for conservation and sustainable use and under imminent threat or need of protection or effective management. In these situations, it may be appropriate to consider an 'outof-kind' offset that involves 'trading up'; i.e., where the offset targets biodiversity of higher priority than that affected by the development project'.

In relation to the situation of no suitable offset sites being available to protect, Blackmore (2020) makes the argument that sometimes a proposed development may be essential or at least clearly in the public good, in which case like for better offsets may be acceptable and appropriate. The public good is also invoked in the EU test of IROPI (Imperative Reasons of Overriding Public Interest), which must be demonstrated in cases in which proposed developments represent a threat to the integrity of Natura 2000 sites, designated under either the Birds Directive or the Habitats Directive, in any state of the EU (Council of the European Communities 1992). Blackmore (2020) goes on to argue that the offset itself must be a public good, going beyond additional conservation outcomes (Principle 2) to be 'overwhelmingly in the public's best long-term biodiversity conservation interest' (p 94).

Brownlie and Botha (2009) describe a system in South Africa whereby biodiversity or regional planning identifies 'offset receiving areas', comprising land available for purchase as offsets. The land is selected because it has biodiversity values that are considered worth protecting, but these values may or may not be the same values as those being impacted by a particular developer. Offsets involving this land could therefore be examples of trading up or like for better. Kiesecker et al. (2010) also make the point that conservation planning, defined as 'the process of locating, configuring, and maintaining areas that are managed to maintain viability of biodiversity and other natural features' (p 262), provides a structure within which trading up or like for better can be considered. There are obvious challenges in evaluating offsets that are not like-for-like, and hence like-for-like should remain as a fundamental principle unless a strategic biodiversity conservation plan of some form is in place (Gardner et al. 2013).

However, several authors have pointed out that habitat protection offsets may not deliver no net loss (Principle 1). The argument is made that simply adding an equivalent-sized parcel of offset land to the conservation estate or placing a conservation covenant over it will not achieve no net loss unless the biodiversity values on that land were under threat prior to this action being taken, because otherwise the principle of additional conservation outcomes (Principle 2) cannot be demonstrated (Thorn et al. 2018). According to this argument, habitat protection offsets can only be considered valid in areas of high rates of biodiversity loss (Curran et al. 2014; Maron et al. 2015), and the ecological gain must be calculated based on the likely trajectory for the offset land in the absence of the offset action, taking into consideration both threats and management actions, i.e., the counterfactual scenario.

Maron et al. (2018) expand on this argument by distinguishing between Type 1 threats to biodiversity values, which are those subject to regulation that invokes offsetting requirements such as developments being subject to EIA, and Type 2 threats that may not be regulated at all or which are regulated through mechanisms that do not invoke offsets such as impacts due to climate change, some agricultural practices or feral animals and weed invasion. They argue that biodiversity values subject only to Type 1 threats cannot be used as an offset because they are not really under threat, given that if a Type 1 threat were to manifest (say in the form of a proposed development), the developer would be required to offset that impact anyway, so no biodiversity gain is achieved by protecting it (Principle 2). In turn, this means that only Type 2 threats should be considered in the likely trajectory for the reference case, and that offsets resulting from Type 1 impacts can offset Type 2 threats, and potentially slow the rate of biodiversity losses from unregulated threats (Maron et al. 2018). A corollary to this argument is offered by Blackmore (2020) who suggests that regulators would be required to refuse applications for development on previously established offset sites; in other words, regulators should ensure no future Type 1 threats apply to established offset sites (Principle 8). 
Counterfactuals therefore have a central role in the evaluation of potential habitat protection offsets, where counterfactuals are predictions of what would have happened, that is, what trajectory might have been followed in the absence of the offset initiative (Maron et al. 2015, 2016a, b; Arlidge et al. 2018). This includes consideration of environmental change processes (Bull et al. 2013a, b). Sonter et al. (2017) point out how rarely the counterfactuals that underpin offset determinations are made transparent. There are many factors that may affect the trajectory of biodiversity value, including changes in regulation or in management practices, climate change and natural regrowth (Sonter et al. 2017; Blackmore 2020). Sonter et al. 2017, p 318 conclude that, 'Biodiversity offset policies must explicitly define plausible counterfactual scenarios... if they are to genuinely achieve their no net loss objectives'. Yet even if the counterfactual scenarios are explicit, if reality does not follow the predicted scenario, then no net loss may not be achieved. In other words, it may be a case of 'offsetting certain losses against uncertain gains' (Weissgerber et al. 2019, p 237). Counterfactuals play an important role in the Australian Commonwealth biodiversity offsets calculation methodology, outlined in SEWPaC (2012a, b), whereby offset proposals must include an assessment of the likely future quality of the proposed offset site, both without and with the proposed offset.

Multiplier ratios are typically applied when determining how big an area is required to achieve habitat protection (Maron et al. 2012). These multiplier ratios are typically greater than 1:1 to account for factors including uncertainty, contingency, time delays (e.g., in purchasing the land) and the ecological value of the area being impacted in situations in which the offsets are not like-for-like (Moilanen et al. 2009; Gardner and von Hase 2012; Bull et al. 2013a, b; Curran and Hollander 2015). Brownlie and Botha (2009) explain how in the Western Cape province of South Africa different ratios apply to like-for-like offsets depending upon the nature of the loss, which are designed to compensate for background loss and to build in a contingency. The ratios are 30:1 for 'critically endangered' ecosystems (to be considered in exceptional circumstances only), 20:1 for 'endangered' ecosystems and 5:1 for 'vulnerable' ecosystems. A multiplier ratio of more than 1:1 may also be required to ensure additional conservation outcomes (Principle 2) in situations in which the biodiversity values of the offset site are not really greatly threatened or if there are already management actions in progress that are improving biodiversity value (Maron et al. 2015; Thorn et al. 2018). Such considerations are factored into the Australian Commonwealth offsets calculator through the assessment of quality with and without the offset as previously mentioned (SEWPaC 2012a, b).

A further consideration for habitat protection offsets is that the offsets must be protected for the long term, at least as long as the duration of the impact (Principle 8) (Villarroya et al. 2014; Arlidge et al. 2018). Linking the life of the offset to the duration of the impact assumes that the impacts on the development site are in fact reversible and that the site can be fully rehabilitated at the conclusion of activities (Bull et al. 2013a, b). There is an alternative argument that offsets should last 'in perpetuity', often defined as 50-75 years when suitable discounting is applied (BBOP 2012). Some authors use the term 'permanence' (Virah-Sawmy et al. 2014; Moilanen and Kotiaho 2018; Souza and Sánchez 2018), but BBOP (2012) states a preference to avoid this term and instead specify the duration of an offset explicitly.

In any case, the question is raised as to who manages the offset sites over their required lifetime. While developers are considered responsible for offsets under the 'Developer Pays Principle' (analogous to the Polluter Pays Principle), it is also recognised that developers are unlikely to have expertise in conservation (Blackmore 2020). In practice, this often means that developers purchase land as an offset and contribute it to the conservation estate, which in turn requires that conservation agencies need to be resourced to manage it over long time periods (Guillet and Semal 2018). Conservation covenants on private land may be an alternative mechanism to protect the biodiversity values into perpetuity (May et al. 2017), but again require that land holder to manage the site. In this way, developers transfer the responsibility for ensuring the longevity of the offset to appropriate land managers, which mitigates at least some of the risk that the offset will not be maintained for a sufficient time period (Blackmore 2020). The counter argument to this, however, is that the offsets 'saturate the capacity of administrative organisations responsible for nature conservation; they destabilise nature protection associations looking for funding; and they generate ambiguity about protected area policies' (Guillet and Semal 2018, p 86).

Since there is potential that habitat protection offsets are improperly applied by not properly considering the likely threats to the ecological values of an offset site, some authors consider this type of offset to be less desirable than improvement offsets, even though time lags (substitution in time) and uncertainty of outcomes are less of a risk (Curran et al. 2014).

In summary, habitat protection measures should meet the following conditions to be considered offsets rather than compensations:

- The biodiversity values protected and the biodiversity values impacted should be like-for-like, unless there is a defined biodiversity strategy or plan whose objectives could be achieved by allowing trading up or like for better, and appropriate means of evaluating the value of the offset in relation to the impact are available (the Principle of Like-for-Like). 
- Offset ratios should be at least $1: 1$, adjusted for the relative quality of the biodiversity in question and its trajectory, time delays, uncertainty and contingency in order to achieve no net loss and additionality (Principles 1 and 2).

- Plausible counterfactual scenarios should be clearly articulated in order to demonstrate no net loss and additionality (Principles 1 and 2).

- A proposed offset site must be subject to high rates of biodiversity loss from Type 2 (unregulated) threats from which it can be protected in order to achieve no net loss and additionality (Principles 1 and 2).

- Protection of biodiversity on the offset site must be guaranteed for at least the duration of the impact requiring the offset if the impact site can be fully rehabilitated, or in perpetuity if not. This may require measures such as contributing the land to the conservation state or applying conservation covenants, coupled with adequate funding for ongoing management (Principle 8).

The articulation of these conditions has implications for offsetting practice. In the case of EIA, for example, it implies that full details of a biodiversity offset proposal should be available at the time of the EIA approval decision, to ensure that all these conditions can be met. If they cannot, then the proposed measure can only be considered a compensation measure but not an offset. The point has also been made in the literature that habitat protection offsets may also have social impacts and/or economic implications (Ives and Bekessy 2015; Bidaud et al. 2017; Taherzadeh and Howley 2018; Thorn et al. 2018; Griffiths et al. 2019), which should also be considered as part of the decisionmaking process and thus be subject to public participation (de Witt et al. 2019).

\section{Improvement}

As described previously, improvement measures can include ecological restoration of degraded habitat, the creation of an entirely new habitat or threat management, such as removal of weeds and feral animals, noting once again that restoration in this case does not mean rehabilitation of the impacts caused by the development (that being simply step 3 of the mitigation hierarchy (CEQ 1978)), but rather must constitute improvement of biodiversity values in another place as a compensatory measure (Maron et al. 2012; Holmes et al. 2016; May et al. 2017; Bezombes et al. 2019). Some authors (e.g., Jacob et al. 2016) include translocation of species from the development site to an alternative site, although we consider this as an impact minimisation measure and not a compensation measure.

As noted earlier, some authors have expressed a preference for improvement offsets over habitat protection offsets because it can be more clear that a real biodiversity benefit is being achieved (Curran et al. 2014; Weissgerber et al. 2019), while others only include improvement offsets in their typologies (Bezombes et al. 2019). Conversely, Brownlie and Botha (2009) note that improvement offsets requiring active creation or restoration of habitat are not considered viable in South Africa as a developing country with capacity constraints.

As previously mentioned, as well as being a substitution in place, improvement offsets also usually represent substitutions in time, because the outcomes may not be fully achieved until well after the offset-requiring impact has occurred 'since processes such as soil formation, tree growth, and the development of biophysical habitats are slow relative to human time frames' (Taherzadeh and Howley 2018, p 1809). Time lags mean that there is a gap between the ecological costs caused by the impact of development and the ecological gain resulting from the offset initiative (Bidaud et al. 2017).

Some authors go as far as arguing that any time lag is unacceptable and therefore that restoration efforts should be completed prior to the impact being permitted to occur (Walker et al. 2009; Gardner et al. 2013). The Australian Commonwealth environmental offsets policy explicitly encourages the use of 'advanced offsets' that are 'a supply of offsets for potential future use, transfer or sale' to address the time-lag issue (SEWPaC 2012a, b, p 9). Offsets with shorter delivery times, including advanced offsets, may be rewarded in the calculation method to determine offset requirements, thus reducing overall requirements. There are, however, many arguments against the logical extension of advanced offsets, which is 'biodiversity banking' or 'mitigation banking' whereby a third party undertakes the improvement works and then sells credits to developers who need offsets in the future (Levrel et al. 2017). This commodification of biodiversity raises ethical concerns (Levrel et al. 2017), is not guaranteed to deliver a like-forlike offset (the Principle of Like-for-Like) or no net loss (Principle 1) (Dupont 2017) and may also violate Principle 2 if the improvement efforts would have happened anyway, for example through voluntary activity (Maron et al. 2012).

A time lag might be considered acceptable under some circumstances if the outcome of no net loss (Principle 1) is ultimately guaranteed, but there are several challenges here. The first is that improvement initiatives are grounded in the assumption that it is possible to restore or recreate ecosystems in the first place, whereas in reality, this is extremely difficult due to both the science and the practical experience being in fledgling states (Maron et al. 2012). Rates of success have been found to be highly variable in practice (Maron et al. 2012), and on this basis, Gardner et al. (2013) suggest that some proposed improvement initiatives may simply be technically infeasible and therefore should not be 
accepted as offsets. Maron et al. (2012) emphasise the importance of adaptive management in ensuring offset viability.

The complexity of determining at what level 'no net loss' should apply, as discussed in 'Offsets versus compensation' above, clearly poses challenges for the evaluation and verification of improvement offset measures. Maron et al. 2012, p 142 identify a number of different evaluation methods, which may be based on 'particular ecological functions, size or viability of threatened species populations, and the extent and/or 'quality' of vegetation associations and habitat types' or alternatively an index that combines these factors. Weissgerber et al. (2019, p 237) add to the debate about verification by arguing that in order to demonstrate no net loss 'the restored ecosystem should not only equal the original or reference ecosystem as usually assumed, but rather the original state of degradation of the ecosystem used for offsetting should be of the same level as the impacted ecosystem after development', i.e., the 'delta' in terms of biodiversity values before and after the impact and restoration initiative should be comparable between the impacted and the restored site. In summary, it is important that clear objectives in terms of biodiversity outcomes are established upfront for restoration initiatives, together with clear evaluation methods to determine whether or not the objectives have been achieved.

In addition to uncertainties about the technical feasibility of achieving defined biodiversity outcomes, there are also uncertainties associated with ongoing management. As is the case for habitat protection initiatives, improvement initiatives must deliver long-term biodiversity outcomes in order to be considered offsets (Principle 8). This requires ongoing management, which in turn raises questions about who should be responsible for this. As discussed in the previous section, developers are primarily responsible for offsets but are unlikely to have expertise in maintaining biodiversity (e.g., as required for habitat protection offsets), much less improving it (Blackmore 2020). This means that governments are likely to have to assume responsibility for the offset at some point. While developers may be required to contribute funding to conservation agencies for this purpose, some authors (e.g., Gordon et al. 2015) also see perverse outcomes here, whereby conservation capacity and resources are shifted away from ongoing programmes to meet the need for offsets, thus violating the requirement that offsets be additional to what would have happened anyway (Principle 2).

Several ways of addressing the inherent uncertainty associated with improvement initiatives, as well as the timelag issue, have been proposed. These include developers being required to purchase insurance to cover the risk that the offset does not achieve its defined objectives, establishing biodiversity banking schemes as already discussed, time discounting and endowment funds (Maron et al. 2012; Blackmore 2020). By far, the most common approach, however, is to apply significant multiplier ratios (logically greater than those applied for habitat protection initiatives) when establishing restoration offset requirements (Moilanen et al. 2009; Blackmore 2020). Although multiplier ratios do not guarantee no net loss (Walker et al. 2009), they do provide some degree of insurance, or 'bet-hedging strategy' (Moilanen et al. 2009, p 476), particularly in the case of creation of a new habitat (Moilanen and Kotiaho 2018). The literature argues that multiplier ratios should be calculated based on factors such as the likelihood of success both of the initial work and the ongoing management and length of time lags (Maron et al. 2012; Curran et al. 2014). Moilanen et al. (2009) found that 'fair' offset ratios might range from two to several hundred when all relevant considerations are factored in and make the point that if there is too long a gap between impact and offset, then the proposed offset might not be valid at all. Not all offset guidance reflects the many reasons why multiplier ratios might be required, however. While the Australian Commonwealth offsets calculator does (SEWPaC 2012a, b), the UK Environment Bill 2020 (delayed in its introduction to parliament due firstly to Brexit and then to Covid-19) mandates $110 \%$ net gain based on a biodiversity metric calculation (Crosher et al. 2019), which does not include the kinds of considerations discussed here.

In summary, improvement measures should meet the following conditions to be considered offsets rather than compensations:

- Improvement offset proposals must have a good chance of success within a reasonable time frame.

- Ideally, biodiversity outcomes should be achieved prior to the offset-requiring impact occurring, or if this is not possible, a fair multiplier ratio should be applied.

- Fair ratio multipliers should also be applied to account for the likelihood of success, both of the original work and of long-term management, as well as any time lags, and the rationale for these ratios should be explicit.

- Clear methods should be available for the evaluation of no net loss, which should include diversity of species, population sizes and areas and ecological functioning, and the evaluation process should take into consideration the 'delta' in terms of biodiversity values before and after the impact and restoration initiative between the impacted and the restored site.

- Ongoing adaptive management measures must be in place to ensure that long-term biodiversity outcomes can be achieved.

- Improvement measures should be additional to and not detract from other biodiversity conservation activities, and this must be funded appropriately by the developer. 


\section{Other Compensation Measures}

Measures that are compensations but not offsets may include research, education or financial contributions, as well as habitat protection and improvement measures that fall short of the conditions outlined in the previous sections. Research could include taxonomic research into particular species, ecological studies or management studies (May et al. 2017), or research into ecological restoration as a necessary precursor to undertaking restoration activities (Maron et al. 2012). Education could include providing interpretative information in protected areas, or informing visitors to such areas about the ways to minimise impacts on the environment. Financial contributions could be made into a strategic offset fund, or directly to conservation agencies for management of conservation initiatives.

Defined in this way, each of these is a substitution in kind between different forms of capital, i.e., natural capital for human capital in the form of knowledge, or financial capital, and none is consistent with the principles of no net loss (Principle 1) or the Principle of Like-for-Like. However, they may be stepping stones or serve to benefit an actual offset if there is an appropriate 'line of sight' from the measure to biodiversity outcomes. For example, if developers were required to first conduct research into the best way to eliminate feral pests from an offset site, or into ecological restoration techniques and then to implement the findings of this research, then this could inform an improvement offset. Similarly, if funds were provided to a conservation agency for the express purpose of managing an offset site donated by the developer to the conservation estate, then this could benefit a habitat protection offset. These approaches do, however, have unknown or uncertain outcomes and they potentially introduce a significant time lag between the offset-requiring impact and the biodiversity outcome, in addition to those inherent in improvement initiatives.

It is acknowledged that taxonomic or ecological research may not be directly implementable in the short term by a developer, but may instead indirectly contribute to better conservation practices in the long term. There would be no 'line of sight' from such a research contribution to a specific biodiversity outcome, so it could not be considered an offset but may be an important part of an overall offset package. The same could apply to educational initiatives. The value of such compensations was recognised in the original Western Australian guidance on offsets (WA EPA 2006), which spoke of direct offsets (or 'true' offsets) and indirect offsets (other compensations). Indirect offsets were required as a supplement to direct offsets in the interests of achieving a net positive biodiversity outcome.

Payment into strategic funds may be perceived as the developer abdicating responsibility for biodiversity outcomes to another entity, such as a conservation agency. Such an approach may however be the only option available in situations in which no suitable land is available to deliver a habitat protection offset, or when improvement offsets are found to be technically infeasible. They could potentially deliver significant biodiversity benefits if the funds go towards measures that address the decline of biodiversity values and contribute to no net loss at a more strategic level (Maron et al. 2018) and perhaps could constitute a 'like for better' or 'trading up' offset (Blackmore 2020). While such an approach will not necessarily deliver like-for-like outcomes, it may once again be a valuable component of an offsets package. The Australian Commonwealth offsets policy, for example, allows $10 \%$ of an overall offsets package for a particular development to be delivered through such 'other compensatory measures' (SEWPaC $2012 a, b)$. The guidance does highlight that the compensatory measures 'do not directly offset the impacts on the protected matter' ( $p$ 9), but includes these measures in its offset typology, implying that they are actually an offset, illustrating our point about conceptual ambiguity in offset policy and guidance.

The Pilbara Environmental Offsets Fund (PEOF) in Western Australia is one example of a strategic fund (Government of Western Australia). The Pilbara Region in the northwest of the state is a mineral extraction centre and a biodiversity hotspot, with complex land tenure arrangements that make it difficult to find suitable sites for habitat protection or improvement offsets. The PEOF is in its very early stages, so the extent to which it is able to deliver offsets as we have defined here, remains to be seen.

\section{Conclusions}

Biodiversity offsetting has proved to be both widespread and contentious in recent years. Our starting point in this paper was the recognition that despite a broad understanding that not all measures designed to compensate for biodiversity loss due to development can be considered to be offsets, since they do not necessarily embody important principles and criteria, there is a lack of agreed understanding of the specific conditions that offset measures should meet, and that this ambiguity and vagueness is reflected in much policy and guidance on biodiversity offsets. Through a review of the considerable and rapidly expanding volume of research work and conceptual contributions to the literature, this paper has established a clear framework articulating the conditions under which compensation measures can be considered offsets potentially able to deliver no net loss of biodiversity.

We have drawn on our knowledge of offset policy and guidance in parts of the world in which we work to present 
illustrative examples of some of our key points. In some cases, we found clarity and precision, and in others ambiguity and lack of rigour. This small sample highlights the opportunity that exists to improve how decision-making around biodiversity offsets is undertaken.

Acknowledging the many reservations about the practicalities, as well as the ethical basis, of many biodiversity offsets and compensation initiatives expressed by conservation biology researchers, we consider that biodiversity offsets are almost certainly here to stay. On this basis, the primary objective should be to ensure that offsets have as a high a chance as possible of delivering the desired biodiversity outcomes. We argue that conceptual clarity in offset policy and guidance is an essential prerequisite to achieving this goal. To this end, we offer our framework researchers and policy makers as a vital tool to support the review and ongoing development of offset policy and guidance around the world, so that it can become an effective foundation for the best possible practice of biodiversity offsets.

\section{Compliance with Ethical Standards}

Conflict of Interest The authors declare that they have no conflict of interest.

Publisher's note Springer Nature remains neutral with regard to jurisdictional claims in published maps and institutional affiliations.

\section{References}

Apostolopoulou E, Adams WM (2017) Biodiversity offsetting and conservation: reframing nature to save it. Oryx 51(1):23-31

Arlidge WNS et al. (2018) A global mitigation hierarchy for nature conservation. BioScience 68(5):336-347

BBOP (2009a) The relationship between biodiversity offsets and impact assessment: a BBOP resource paper. Business and Biodiversity Offsets Programme, Washington, DC. https://www.foresttrends.org/wp-content/uploads/bbop/the-relationship-betweenbiodiversity-offsets-and-impact-assessment-pdf.pdf. Accessed 26 Oct 2020

BBOP (2009b) Biodiversity offset design handbook. Business and Biodiversity Offsets Programme, Washington, D.C., https://www. forest-trends.org/wp-content/uploads/imported/biodiversityoffset-design-handbook-pdf.pdf. Accessed 26 Oct 2020

BBOP (2012) Standard on biodiversity offsets. Business and Biodiversity Offsets Programme

Bezombes L et al. (2019) Do biodiversity offsets achieve no net loss? An evaluation of offsets in a French department. Biol Conserv 231:24-29

Bidaud C et al. (2017) The sweet and the bitter: intertwined positive and negative social impacts of a biodiversity offset. Conserv Soc 15(1):1-13

Bigard C et al. (2017) The inclusion of biodiversity in environmental impact assessment: policy-related progress limited by gaps and semantic confusion. J Environ Manag 200:35-45

Blackmore A (2020) Towards unpacking the theory behind, and a pragmatic approach to biodiversity offsets. Environ Manag 65 (1):88-97
Brown MA et al. (2014) Implementing ecological compensation in New Zealand: stakeholder perspectives and a way forward. J R Soc NZ 44(1):34-47

Brownlie S, Botha M (2009) Biodiversity offsets: adding to the conservation estate, or 'no net loss'?. Impact Assess Proj Apprais 27 (3):227-231

Brownlie S et al. (2013) Biodiversity tradeoffs and offsets in impact assessment and decision making: can we stop the loss?. Impact Assess Proj Apprais 31(1):24-33

Brownlie S et al. (2017) Biodiversity offsets in South Africa-challenges and potential solutions. Impact Assess Proj Apprais 35(3):1-9

Bull JW, Strange N (2018) The global extent of biodiversity offset implementation under no net loss policies. Nat Sustain 1 (12):790-798

Bull JW et al. (2013a) Biodiversity offsets in theory and practice. Oryx 47(3):369-380

Bull JW et al. (2013b) Conservation when nothing stands still: moving targets and biodiversity offsets. Front Ecol Environ 11 (4):203-210

CEQ (1978) National Environmental Policy Act—regulations. C. f. E. Quality

Council of the European Communities (1992) Council Directive 92/ 43/EEC of 21 May 1992 on the conservation of natural habitats and of wild fauna and flora. Off J Eur Communities L206:7-50. $(22 / 07 / 1992)$

Crosher I et al. (2019) The Biodiversity Metric 2.0: auditing and accounting for biodiversity value. User guide (Beta Version, July 2019). 2020. http://publications.naturalengland.org.uk/file/536620 5450027008

Curran G, Hollander R (2015) 25 Years of ecologically sustainable development in Australia: paradigm shift or business as usual? Australas J Environ Manag 22(1):2-6

Curran $\mathrm{M}$ et al. (2014) Is there any empirical support for biodiversity offset policy? Ecol Appl 24(4):617-632

de Witt M, Pope J, Retief F, Bond A, Morrison-Saunders A, Steenkamp C(2019) Biodiversity offsets in EIA: Getting the timing right Environ Impact Assess Rev 75:1-12

DEA (2017) Draft national biodiversity offset policy. Department of Environmental Affairs. Pretoria Gov Gaz 267(No. 40733):1-34

DEADP (2007) Provincial guideline on biodiversity offsets edition 2. Provincial Government of the Western Cape, Department of Environmental Affairs \& Development Planning, Cape Town, Republic of South Africa

Dupont V (2017) Biodiversity offsets in NSW Australia: the biobanking scheme versus negotiated offsets in urban areas. J Environ Law 29(1):75-100

Gardner T, von Hase A (2012) Key ingredients for biodiversity offsets to achieve no net loss. Department of Conservation, Wellington

Gardner T et al. (2013) Biodiversity offsets and the challenge of achieving no net loss. Conserv Biol 27(6):1254-1264

Gibson R, Hassan S, Holtz S, Tansey J, Whitelaw G (2005) Sustainability assessment: Criteria and processes. London: Earthscan

Gordon A et al. (2015) Perverse incentives risk undermining biodiversity offset policies. J Appl Ecol 52(2):532-537

Government of Western Australia Pilbara Environmental Offsets Fund - overview. Department of Water and Environmental Regulation. https://www.wa.gov.au/sites/default/files/2020-07/DWERPEOF-Overview.pdf. Accessed 19 Oct 2020

Griffiths VF et al. (2019) No net loss for people and biodiversity. Conserv Biol 33(1):76-87

Guillet F, Semal L (2018) Policy flaws of biodiversity offsetting as a conservation strategy. Biol Conserv 221:86-90

Hayes N, Morrison-Saunders A (2007) Effectiveness of environmental offsets in environmental impact assessment: practitioner perspectives from Western Australia. Impact Assess Proj Apprais 25(3):209-218 
HM Government (2011) The natural choice: securing the value of nature. 2020. https://assets.publishing.service.gov.uk/government/ uploads/system/uploads/attachment_data/file/228842/8082.pdf

Holmes ND et al. (2016) The potential for biodiversity offsetting to fund invasive species eradications on islands. Conserv Biol 30 (2):425-427

Ives CD, Bekessy SA (2015) The ethics of offsetting nature. Front Ecol Environ 13(10):568-573

Jabareen Y (2009) Building a conceptual framework: philosophy, definitions, and procedure. Int J Qual Methods 8(4):49-62

Jacob C et al. (2016) The effectiveness of the mitigation hierarchy in environmental impact studies on marine ecosystems: a case study in France. Environ Impact Assess Rev 60:83-98

Kiesecker JM et al. (2010) Development by design: blending landscape-level planning with the mitigation hierarchy. Front Ecol Environ 8(5):261-266

Levrel $\mathrm{H}$ et al. (2017) Should we be wary of mitigation banking? Evidence regarding the risks associated with this wetland offset arrangement in Florida. Ecol Econ 135:136-149

Maron M et al. (2012) Faustian bargains? Restoration realities in the context of biodiversity offset policies. Biol Conserv 155:141-148

Maron $\mathrm{M}$ et al. (2015) Locking in loss: baselines of decline in Australian biodiversity offset policies. Biol Conserv 192:504-512

Maron $\mathrm{M}$ et al. (2016a) Taming a wicked problem: resolving controversies in biodiversity offsetting. BioScience 66(6):489-498

Maron $\mathrm{M}$ et al. (2016b) Taming a wicked problem: resolving controversies in biodiversity offsetting. BioScience 66(6):489

Maron M et al. (2018) The many meanings of no net loss in environmental policy. Nat Sustain 1(1):19-27

May J et al. (2017) Are offsets effective? An evaluation of recent environmental offsets in Western Australia. Biol Conserv 206:249-257

McKenney BA, Kiesecker JM (2010) Policy development for biodiversity offsets: a review of offset frameworks. Environ Manag 45 (1):165-176

Moilanen A, Kotiaho JS (2018) Fifteen operationally important decisions in the planning of biodiversity offsets. Biol Conserv 227:112-120

Moilanen A et al. (2009) How much compensation is enough? A framework for incorporating uncertainty and time discounting when calculating offset ratios for impacted habitat. Restor Ecol 17(4):470-478

Morgan RK (2012) Environmental impact assessment: the state of the art. Impact Assess Proj Apprais 30(1):5-14

Morrison-Saunders A, Pope J (2013) Conceptualising and managing trade-offs in sustainability assessment. Environ Impact Assess Rev 38:54-63
NSW DLWC (2001) Offsets, salinity and native vegetation discussion paper, report: HO/08/01, New South Wales Department of Land Water Conservation, Sydney

NSW EPA (2002) Green offsets for sustainable development-concept paper. New South Wales, Environmental Protection Authority

Primmer E et al. (2019) Institutions for governing biodiversity offsetting: an analysis of rights and responsibilities. Land Use Policy 81:776-784

SEWPaC (2012a) Environment protection and biodiversity conservation act 1999 environmental offsets policy. Government of Australia, Department of Sustainability, Environment, Water, Population and Communities, Canberra, Australia

SEWPAC (2012b) How to use the offsets assessment guide. Australian Government, Department of Sustainability, Environment, Water, Population and Communities, Canberra, Australia

Sonter LJ et al. (2017) Biodiversity offsetting in dynamic landscapes: influence of regulatory context and counterfactual assumptions on achievement of no net loss. Biol Conserv 206:314-319

Souza BA, Sánchez LE (2018) Biodiversity offsets in limestone quarries: investigation of practices in Brazil. Resour Policy $57: 213-223$

Spash CL (2015) Bulldozing biodiversity: the economics of offsets and trading-in nature. Biol Conserv 192:541-551

Taherzadeh O, Howley P (2018) No net loss of what, for whom?: stakeholder perspectives to biodiversity offsetting in England". Environ Dev Sustain 20(4):1807-1830

Ten Kate K et al. (2004) Biodiversity offsets: views, experience, and the business case. IUCN-The World Conservation Union

Thorn S et al. (2018) Effectiveness of biodiversity offsets: an assessment of a controversial offset in Perth, Western Australia. Biol Conserv 228:291-300

UNEP (2018) Assessing environmental impacts-a global review of legislation. United Nations Environment Program, Nairobi

Villarroya A et al. (2014) Policy development for environmental licensing and biodiversity offsets in Latin America. PloS ONE 9 (9):e107144

Virah-Sawmy M et al. (2014) Mining and biodiversity offsets: a transparent and science-based approach to measure "no-net-loss". J Environ Manag 143:61-70

WA EPA (2006) Environmental offsets position statement no 9. Environmental Protection Authority of Western Australia, Perth

Walker S et al. (2009) Why bartering biodiversity fails. Conserv Lett 2 (4): 149-157

Weissgerber M et al. (2019) Biodiversity offsetting: certainty of the net loss but uncertainty of the net gain. Biol Conserv 237:200-208 